\title{
OS DESASTRES DA GUERRA: ICONOLOGIA POLÍTICA DO SOFRIMENTO
}

THE WAR DISASTER: ICONOLOGY SUFFERING POLITICAL

\author{
Cristina Susigan* \\ csusigan@gmail.com
}

RESUMO: Mesmo antes do advento da fotografia, artistas registravam os horrores da guerra através de sua arte, como forma de dar a ver a dor dos outros e perpetuar um momento histórico. Francisco de Goya, pintor espanhol, é um exemplo deste registro. Através de pinturas e gravuras que demonstravam de forma crua e forte as crueldades cometidas duranre a invasão francesa em Espanha, descreve a guerra como algo inútil, cruel e sem glória. Antes dele, em 1633, Jacques Callot, já fizera gravuras sobre os horrores da guerra. Mas será com o advento da fotografia, como meio técnico que capta o real de forma tão viva e verdadeira como a própria natureza, que o registro fotográfico se torna uma forma específica de representar a catástrofe. Neste artigo tentaremos relacionar formas de representação através das gravuras de Goya, os primeiros registros fotográficos de Mathew Brady, na guerra de Secessão americana e a iconologia política de Aby Warburg, como registros da memória.

PALAVRAS-CHAVE: iconologia política, fotografia, gravura

ABSTRACT: Even before the advent of photography, artists recorded the horrors of war through his art, as a way to see the pain of others and perpetuate a historic moment. Francisco de Goya, Spanish painter, is an example of this record. Through paintings and engravings that showed raw and strongly the cruelties committed during the French invasion of Spain, describes the war as something useless, cruel and without glory. Before him, in 1633, Jacques Callot, had done engravings on the horrors of war. But is with the advent of photography, as technical means that captures the real so true and living way the very nature, the photographic record becomes a specific way of representing the disaster. In this article we will try to relate forms of representation through the prints Goya, the first photographic records of Mathew Brady, the American Civil War and political iconology Aby Warburg, as memory records.

KEYWORDS: political iconology, photography, engraving

"Transformar é o que toda a arte faz, mas a fotografia que dá testemunho do calamitoso e do condenável é muito criticada se parece estética, ou seja, demasiado semelhante à arte. È o poder dúplice da fotografia: gerar documentos e criar obras de arte visual." Susan Sontag

Desde o início das artes o ser humano costuma representar o sofrimento, entretanto, segundo Susan Sontag em Olhando o sofrimento dos outros, apenas o sofrimento fruto da ira, divina ou humana, é "digno" de ser representado. Não existe ou é muita rara uma pintura que represente um acidente, por exemplo. Várias obras de arte como a pintura $O$ Dragão devorando os companheiros de Cadmo, 1588, do artista Goltzius

\footnotetext{
*Professora e pesquisadora na Universidade Mckenzie de S.Paulo. Doutoranda no Programa de Pós Graduação em Educação, Arte e História da Cultura da mesna instituição.
} 
(Figura 01), representa, como o próprio título diz, um dragão devorando alguns homens de maneira um pouco chocante, ainda mais se pensarmos na época em que foi pintada.

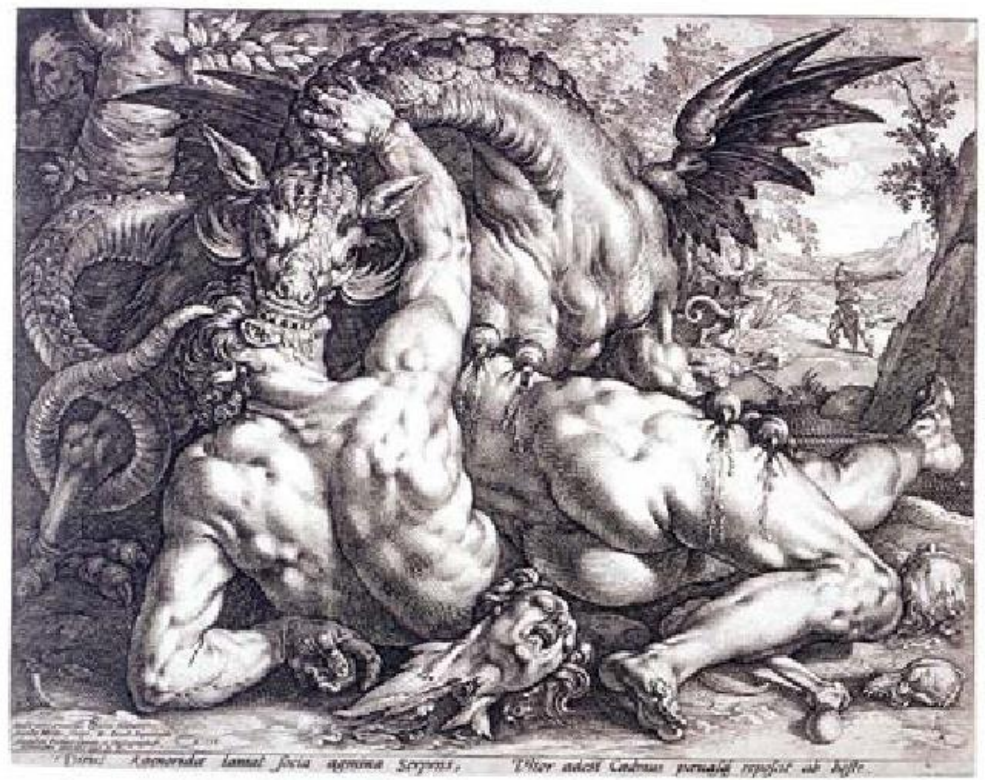

Figura 01 - O Dragão Devorando os Companheiros de Cadmo, 1588, de Hendrik Goltzius ${ }^{1}$

Com a fotografia acontece algo parecido: não existe uma regra que proíba determinados tipos de imagens. Crianças mortas, corpos estraçalhados, membros decepados: o fotógrafo pode clicar qualquer uma dessas cenas sem que haja uma censura ou uma lei que o proíba, apenas o bom senso e o senso crítico julgam o profissional.

Talvez seja para chocar as pessoas e mostrar os horrores que as guerras provocam ou ainda por um simples prazer mórbido em mostrar a "desgraça", mas de fato não existe "nenhuma acusação moral que recai sobre a representação dessas crueldades. Apenas uma provocação: você é capaz de olhar para isso? " (SONTAG, 2003, p. 38)

Seguindo a linha de questionamento sobre crueldade, Sontag remete a questão histórica das representações de guerra. Já no século XVII Jaques Callot publica uma série de 18 gravuras em água-forte intitulada As misérias e os infortúnios da guerra que representavam a invasão das tropas francesas e a ocupação francesa ao Ducado de Lorraine dando ênfase aos horrores da guera. A mesma linha de trabalho é feita pelo alemão Hans Ulrich Franck, que em 1643, perto do fim da Guerra dos 30 Anos, publica 25 gravuras em água-forte sobre esse conflito.

\footnotetext{
${ }^{1}$ https://www.academia.edu/7194083/DIANTE_DA_DOR_DOS_OUTROS. Acesso em 01/2015, s/n
} 
Entre os anos 1810 e 1820, o espanhol Francisco de Goya representa a invasão napoleônica a Espanha também em água-forte, intitulada de As Desgraças da Guerra, mas existia um diferencial em seu trabalho. A representação era mais real, com o cenário em menor destaque e em mais evidência as pessoas e as crueldades da guerra. De acordo com Sontag, "Goya marca na arte, um novo padrão de receptividade aos sofrimentos". (2003, p. 40)

Evoluindo da água-forte para a fotografia, os primeiros registros fotográficos de guerra foram em 1855, na Guerra da Criméia, onde Roger Fenton, considerado o primeiro fotógrafo de guerra, foi enviado como fotógrafo oficial pelo governo britânico. Entretanto, a guerra não era bem vista pela sociedade, pois já houvera muitas perdas e poucos benefícios estavam sendo vistos. Por causa disso e da falta de mobilidade que o equipamento oferecia (muito pesado e demorado), Fenton fotografou o lado mais "tranqüilo" da guerra, ou seja, os soldados em seu momento de descanso, lendo e conversando.

As fotografias de guerra continuaram a ser feitas, mas a primeira tentativa de tirálas em grande escala foi feita durante a Guerra Civil Americana pelo fotógrafo Mathew Brady e seus "subordinados" Alexander Gardner e Timothy O’Sullivan. Para Brady "a câmera é o olho da história". Um pouco diferente de Fenton, Brady chegou mais perto da guerra e fotografou seu lado "feio", mostrando corpos sem vida dos soldados.

Aby Warburg, entretanto, não estará nas trincheiras para fazer o registro da guerra in loco, mas fará uma iconologia política sobre a guerra reunindo entre 1914-1918 mais de cinco mil imagens referentes ao evento: desde recortes de jornal, cartões e selos postais, até fotografias compradas dos serviços de imagens do exército alemão. $\mathrm{O}$ trabalho realizado por Warburg nos anos do conflito, estariam localizados dentro de um fenômeno propriamente alemão, a formação dos Kriegssammlugen, ou, coleções de guerra. Este interesse por montar coleções e arquivos sobre a guerra seria uma faceta do que Didi-Huberman identificou como a sobrevivência do conflito, psicologicamente, culturalmente e politicamente ao silêncio das armas.

As gravuras de Goya, as fotografias de guerra de Brady e a iconologia política reunidas posteriormente no Atlas Mnemosyne são testemunhos da história e do sofrimento da humanidade, meios diferentes de fazer o registro de um período histórico, não em modo de classificá-lo e encerrá-lo, mas de reposicionar conforme as mudanças culturais e técnicas. 


\section{As gravuras de Goya: registros de guerra?}

No livro Olhando o sofrimento dos outros, Sontag (2003) discorre sobre a fotografia como uma forma específica de representar a catástrofe. Na prancha da coleção de Goya, Os desastres da guerra (1810-20), que ilustra a capa do livro, observamos um homem em trajes militares recostado a contemplar outro homem que jaz enforcado a menos de um metro de distância. Estariam frente a frente vítima e seu perpetrador? Ou aquele observa com o interesse de tentar experienciar a dor do outro? Através dessa imagem, a autora coloca o problema da alteridade em que "nós" são aqueles que observam numa posição segura os "outros" assolados pelas catástrofes.

Francisco de Goya, não deve, provavalmente ter testemunhado muita coisa, afinal ele não era um correspondente de guerra e sua idade já avançada na época, 62 anos, manteve-o fora desta luta. No entanto, apesar de ser um pintor da corte, o seu tema favorito foi a guerra - esta mudança foi ocasionada pela doença que o vitimou e o deixou surdo para o resto da sua vida. Segundo Tzvetan Todorov, “(...) Os dois eventos, um puramente privado, o outro ocorrido no grande palco do mundo, contaminando-se um ao outro, devem ter participado simultaneamente da transformação mental que Goya expermentou" (2014, p.40)

Neste período, Goya encheu páginas de seu caderno de esboços com cenas de assassinatos, tortura e violação, desenhos que ele posteriormente vai trasferir depois para gravuras e que não foram encomendadas. Pela primeira vez na história da arte ocidental, há um registro através de imagens que tratam de igual modo os franceses e os seus ideais revolucionários, e os espanhóis com o seu orgulho nacionalista. Mostra a chacina de ambos os lados. O que interessava a Goya era a forma como as pessoas tratam o seu semelhante e o como o caos e a guerra transformam cidadãos pacíficos em seres plenos de atrocidades.

Ao assumir este novo olhar sobre a guerra, Goya encontrou novas formas de representação, como podemos notar na comparação das duas gravuras abaixo de homens enforcados, de Callot (Figura 02) e de Goya (Figura 03): 


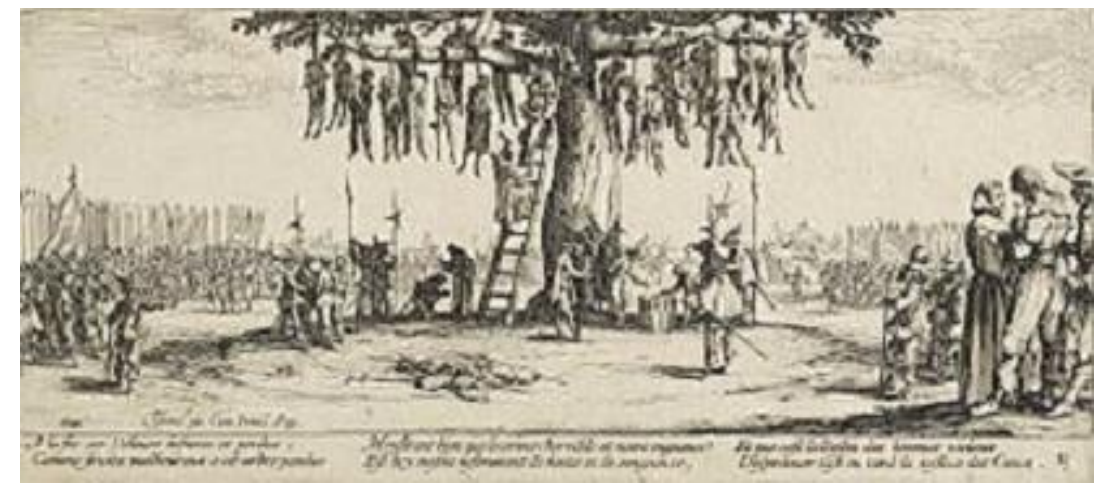

Figura 02 - O Enforcado (de Les Grands Misères de la Guerre), 1633, de Jacques Callot ${ }^{2}$

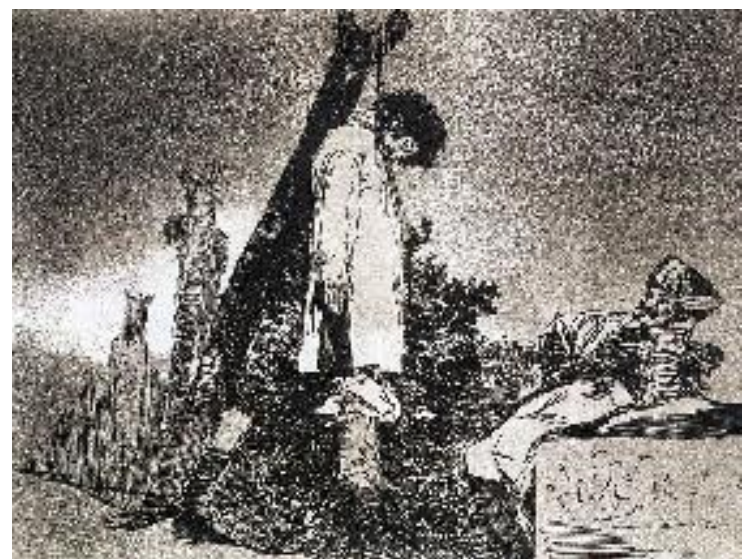

Figura 03 - Aqui também não (Os desastres da guerra 36), 1812-1815, Francisco de Goya ${ }^{3}$

A Figura 02, de Callot, ilustra um enforcamento em massa efetuado na Guerra dos Trinta Anos. Callot manteve o eixo central de sua gravura em um tronco de árvore, mantendo a cena de morte a uma certa distância. Na gravura de Callot, de um ponto de vista formal, existe uma ordem nesta cena de assassinato em massa, pois os enforcados estão distribuídos de forma uniforme. E a sensação de ordem é confirmada pelos versos que acompanham a imagem e identificam os enforcados como bandidos que tiveram o fim que mereciam. Na Figura 03, de Goya, este colocou o enforcado em primeiro plano, bem à frente do espetador. Em Goya, tudo parece despropositado e fora do lugar, oferecendo apenas fragmentos de paisagem. E Goya caracterizou cada uma das suas gravuras com frases breves.

Apesar de Os desastres da guerra serem muitas vezes considerados registros da guerra e das suas atrocidades, com seus cadáveres, feridos e famintos, Goya não terá presenciado estas imagens, apesar de frases ditas por ele como: "eu assist a essa cena".

\footnotetext{
${ }^{2}$ https://www.academia.edu/7194083/DIANTE_DA_DOR_DOS_OUTROS. Acesso em 01/2015, s/n ${ }^{3}$ TODOROV, 2014, p. 138
} 
Todorov analisa este olhar de Goya diante da guerra como um questionamento da hierarquia da pintura e da ordem social, e afirma:

(...) Tais cenas já não correspondem a nenhum repertório de signos convencionais. Goya as representa sem nos indicar qual é o seu objetivo. Sentiu que elas revelavam algo de essencial à condição humana; isso lhe bastou para que ele julgasse útil colocá-las sob os nossos olhos. (TODOROV, 2014, p.50)

Como visto, até o início do século XIX, as guerras haviam sido representadas iconicamente por meio do desenho e da pintura. Contudo, este século traria uma nova técnica de reprodutibilidade da imagem: a fotografia. Neste contexto emerge, também, um debate e uma escrita sobre o objeto fotográfico que, por vieses opostos, acabam convergindo para o que Dubois denomina discurso da mimese. Um discurso que ganha adeptos pelo século XX afora e que ainda pode ser visto na famosa frase do senso comum de que a "imagem fala por mil palavras". A noção de foto-espelho do mundo real, típica do pensamento do XIX, faz parte de uma discussão acerca do estatuto artístico da fotografia em comparação com a pintura. Em síntese, para os otimistas e pessimistas a fotografia é mais real do que a pintura, é objetiva e testemunha, fielmente, o mundo que esteve à frente da máquina.

\section{O Carte-de-Visite vai à Guerra}

Uma primeira tentativa de representação fotográfica de guerra, sistematizada em moldes empresariais foi na Guerra Civil Americana (1861-1865). Mathew Brady foi o fotógrafo protagonista daquele conflito e fazia parte de uma empresa de fotógrafos do lado Norte, responsável, inclusive, pelo retrato oficial do presidente Abraão Lincoln.

As fotografias de guerra de Brady - a maior parte tiradas por Alexander Gardner (1819-1882), Timothy O'Sullivan (ativo de 1840-1882) e George N. Barnard (1819-1902) tratavam de temas convencionais, como acampamentos povoados de oficiais e soldados de infantaria, cidades na zona de guerra, artilharia, barcos, assim como, as mais famosas, soldados mortos da União e Confederados, jazendo no solo bombardeado de Gettysburg e de Antietam.

A novidade para os fotógrafos itinerantes envolvidos na cobertura da guerra, era, digamos, a situação de campos. Acostumados às condições de vida em cidades, tiveram que se transportar e a enorme quantidade de equipamento de que necessitavam, incluindo uma 
carroça-laboratório, para revelarem as fotos mal estas fossem obtidas, por milhares de quilômetros até os acampamentos das tropas. A Guerra da Secessão foi a primeira ocasião da história em que os "fotojornalistas", como conhecemos hoje, correram perigo de vida ao cobrirem um front de batalha.

Além de saírem do estúdio das cidades e de se transportarem para os acampamentos militares, os fotógrafos da guerra souberam incorporar novidades na composição de seus trabalhos, que ganhavam em realismo, deixando de ser apenas "retratos". Até o mais prosaico carte-de-visite 4 passava, por força do momento, a adquirir significado especial como um documento histórico-cultural. Para a fotografia da época, cujo enquadramento e composição eram regidos pela lógica de composição da pintura acadêmica, a realidade sem retoques, captada pelos fotógrafos de Brady, era uma mudança.

Não se deve subestimar a importância do registro fotográfico, em formato de cartede-viste ou por meio de sua cópia e publicação em litografias pela imprensa da época, na formação de uma opinião pública. Brady e outros fotógrafos, por exemplo, devem ter influenciado a opinião dos públicos, ao dar conhecimento fotos do campo de prisioneiros de Andersonville, onde se dizia que morria um prisioneiro a cada onze minutos. As gravuras dos "esqueletos humanos" publicadas, em Junho de 1864, na Leslie's e na Harper's, a partir das fotos, escandalizaram o Norte: não traziam a emoção visceral, intensa e instantânea das fotos-choques, mas ao saber que eram desenhos executados a partir de fotografias a credibilidade e dramaticidade era potenciada.

Talvez a maior herança deixada por essa "febre de imagens" do período foi a possibilidade do seu uso jornalístico. A equipe de Brady documentou, com crueza e sensibilidade, a Guerra de Secessão dos Estados Unidos. Na busca de objetividade, produziram, pela primeira vez, um olhar público para os horrores da guerra, destituídos, pela fotografia, de qualquer nobreza ou heroísmo.

\footnotetext{
${ }^{4}$ Os carte-de-viste eram assim denominados por terem o tamanho de um cartão de visita. Se tornaram populares a partir de 1854, como pequenos retratos. Eram destinados a serem oferecidos a amigos e parentes com com dedicatórias escritas no verso onde aparecia como prova de amizade, despedida, saudação ou simplesmente para marcar um compromisso. Boris Kossoy afirma que "o retrato apresentado dessa forma tornou-se a moda mais popular que a fotografia assistiu em todo o século passado" (KOSSOY, 1980: 29). Seu amplo consumo traria a padronização do produto fotográfico e de seu conteúdo, estereotipando cenários e poses dos retratados
} 
Brady, Gardner e O'Sullivan fotografaram com o compromisso duplo e pioneiro de utilizar-se da imprensa para permitir que um número muito grande de pessoas pudesse ver o que de fato ocorria nos campos de batalha; ao mesmo tempo, suas fotografias documentavam, com cruel clareza e objetividade, suas opiniões sobre a guerra. Segundo Susan Sontag, "por trás da câmera fotógrafica há um agente que, ao acionar o obturador, deixa aflorar toda uma bagagem cultural, seja ela em tom de denúncia, de agressividade e até mesmo de ingenuidade." (SONTAG, 1986, p. 87).

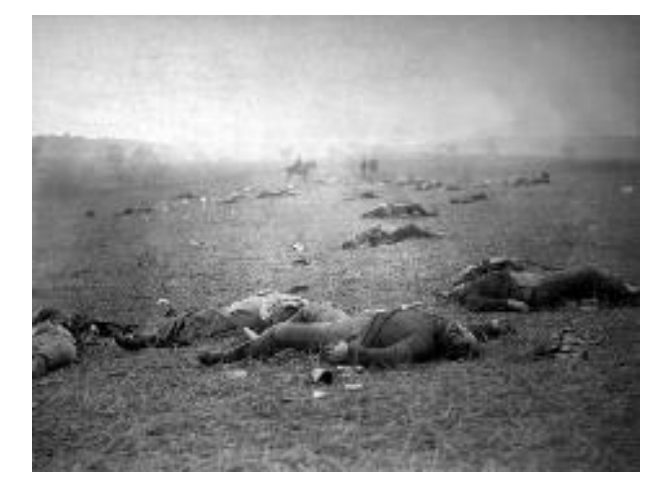

Figura 04 - Batalha de Gettysburg, Mathew Brady ${ }^{5}$

Esta fotografia, de Mathew Brady expressa signos da morte. Embora também tenha fotografado acampamentos, soldados de infantaria, embarcações, cidades, aquele também capturou imagens mais fortes da guerra, ou seja, soldados mortos. Para Sontag (2003, p. 45) a violação de um tabu do registro da guerra se deve aos aspectos do realismo exacerbado bastante impregnados na concepção do fotógrafo. "A câmera é o olho da história", teria afirmado Brady, e só "em nome do realismo, permitiase-exigia-se- que se mostrassem fatos desagradáveis, brutais". (SONTAG, 2003, p. 45). O lugar social de Brady difere do de Fenton. Ele não cobriu a guerra na condição de fotógrafo contratado pelo Estado, e sim, de empresário comercial cujo objetivo era vender as fotografias após a guerra. Inclusive, conforme observa Gisele Frèund (1995), a comercialização das mesmas não correspondeu ao esperado pelo fotógrafo, o que fez com que ele vendesse todas as imagens ao seu principal credor que havia fornecido material para a realização da cobertura da guerra.

Depois da fotografia, a guerra nunca mais seria a mesma. Com o "realismo" pretendido pela foto, o observador era projetado num mundo mais próximo, mais real, mas por vez mais cruel. No mundo da imprensa, com as fotos, o conhecimento, o julgamento e a apreciação deixaram de ser monopolizados pela escrita.

\footnotetext{
${ }^{5}$ http://coral.ufsm.br/lav/noticias1 arquivos/realismo.pdf. Acesso em 01/2015, s/n.
} 


\section{Iconologia política: Atlas}

Em 2011, no seu livro Atlas ou a Gaia Ciência Inquieta, Georges DidiHuberman, historiador da arte e filósofo francês, afirma que: “A Primeira Guerra Mundial não deu a ninguém a possibilidade de permanecer indiferente ou de ficar indemne. De uma maneira ou de outra, todos os habitantes da Europa foram expostos à guerra." (p.189) Este foi o caso de Aby Warburg, historiador de arte e descendente de uma eminente família de banqueiros judeus, que mesmo não tendo lutado nas trincheiras, esteve exposto à guerra.

Desde o início do conflito, Warburg reorganizou o funcionamento da sua investigação, da sua biblioteca, adquirindo obras sobre a guerra, e reunindo inúmeras fotografias. Segundo o autor francês, esta experiência teria sido decisiva, pois levanta a hipótese de que as transformações causadas pela guerra, em Warburg, estariam encarnadas no Atlas Mnemosyne, e na nova metodologia e teoria ali postas em prática. A data em que Warburg iniciou este seu projeto, 1924, marca o término de um período de seis anos em que ele passou acometido de diversos distúrbios psíquicos, culminando com sua internação em Kreutzlingen. Seus problemas começaram a se manifestar em 1918, e há indicações de que estivessem relacionados com a experiência da Guerra Mundial.O método adotado por Warburg seria baseado na ideia de montagem. Os diferentes modos com que as imagens eram montadas nos painéis, as proximidades ou os intervalos entre elas, criariam significados determinados.

O extenso arquivo de imagens que Warburg montou durante a guerra não teria sido a única iniciativa neste sentido. Ao contrário de Warburg, distante do front de guerra, Marc Bloch e Lucien Febvre, os dois grandes historiadores fundadores da École des Annales, combaterem, bem como Ernst Friedrich e o escritor e veterano de guerra. Ernst Jünger. Febvre não chegou a integrar nos seus escritos sua experiência na guerra, ao contrário de Bloch, que elaborou a sua experiência através de numerosos cadernos de notas, desenhando e usando fotografias que ele próprio acumulou durante a guerra. De forma mais sistematizada, Friedrich publicada em 1924, um albúm fotográfico denominado Guerra à guerra, que teve uma excelente recepção na Alemanha de Weimar. O livro traz cerca de 180 fotografias, dois terços das quais de horrores da guerra e a grande maioria, oficialmente censurada durante o conflito. Representações de morte, destruição e mutilação, e 
contraposições de imagens, e de imagens e legendas, denunciam o que seria a insensatez e a crueldade do evento.

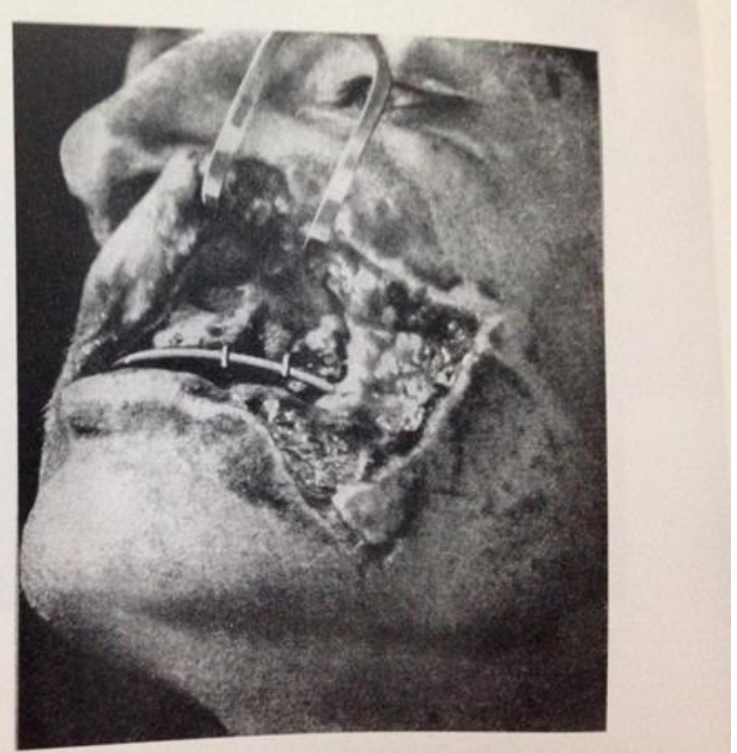

Figura 05 - Guerra à Guerra, 1924, de Ernst Friedrich, Berlim Internationales Kriegsmuseum. ${ }^{6}$

Friedrich baseou a legitimidade de seu ponto de vista político na autoridade da imagem fotográfica. No prefácio do livro, ele chega a afirmar que "no presente e no futuro" todo o "tesouro das palavras" não seria mais suficiente para "pintar corretamente" os horrores da guerra, mas "parte por acidente, parte intencionalmente" uma imagem "objetivamente verdadeira e fiel" da guerra teria sido registrada "pelas incorruptíveis e inexoráveis lentes fotográficas" e publicadas em seu livro, de modo que ninguém poderia afirmar que "não são verdadeiras e não correspondem à realidade. (SANCHEZ, 2002, p. 22)

Em oposição ao álbum de Friedrich, o livro de Jünger em Face da Guerra: Experiências dos Soldados Alemães na Frente de Batalha, publicado em 1930, com cerca de 200 fotografias, têm uma posição nacionalista bem definida, construída por meio de fotografias que, ordenadas de um modo específico, não se detêm nas consequências da guerra, mas buscam passar uma imagem idealizada de glória e honra dos soldados. Ele se apoia no caráter documental e na ideia de veracidade associados à imagem fotográfica, enfatizados pela ordem cronológica e pela implícita ideia de que as imagens são clichês espontâneos. A característica de testemunha da imagem fotográfica é, portanto, enfatizada.

Por sua vez, num âmbito privado, de carácter familiar que a instituição de Warburg funcionava, o historiador reuniu uma documentação vasta, - cerca de 72 caixas com 90.000 
fichas, os ficheiros de guerra (DIDI-HUBERMAN, 2013, p.194) - que iriam dar origem a prancha sobre a iconologia política, que infelizmente não se concretizou devido à morte do estudioso em 1928. E o que estas imagens revelavam? Revelavam o característico olhar warburguiano, o conteúdo crítico que guia o historiador: edifícios antigos ou religiosos, monumentos desmoronados sob os bombardeamentos; colunas dóricas crivadas de balas de metralhadoras; explosões aéreas - uma novidade técnica da guerra moderna; mas também bengalas, recordando-nos, o quanto a guerra pôde destruir, desfigurar, reduzir os homens ao sofrimento da mutilação, de dissemelhança (2013, p.193). Ao contrário das outras coleções, embuídas de conteúdo com fins patrióticos, Warburg, segundo Didi-Huberman, “(...) abria caminho a uma verdadeira iconologia política, (...) a todas as análises históricas e antropológicas que florescem atualmente no domínio das imagens produzidas na época da Grande Guerra." (2013, p.196)

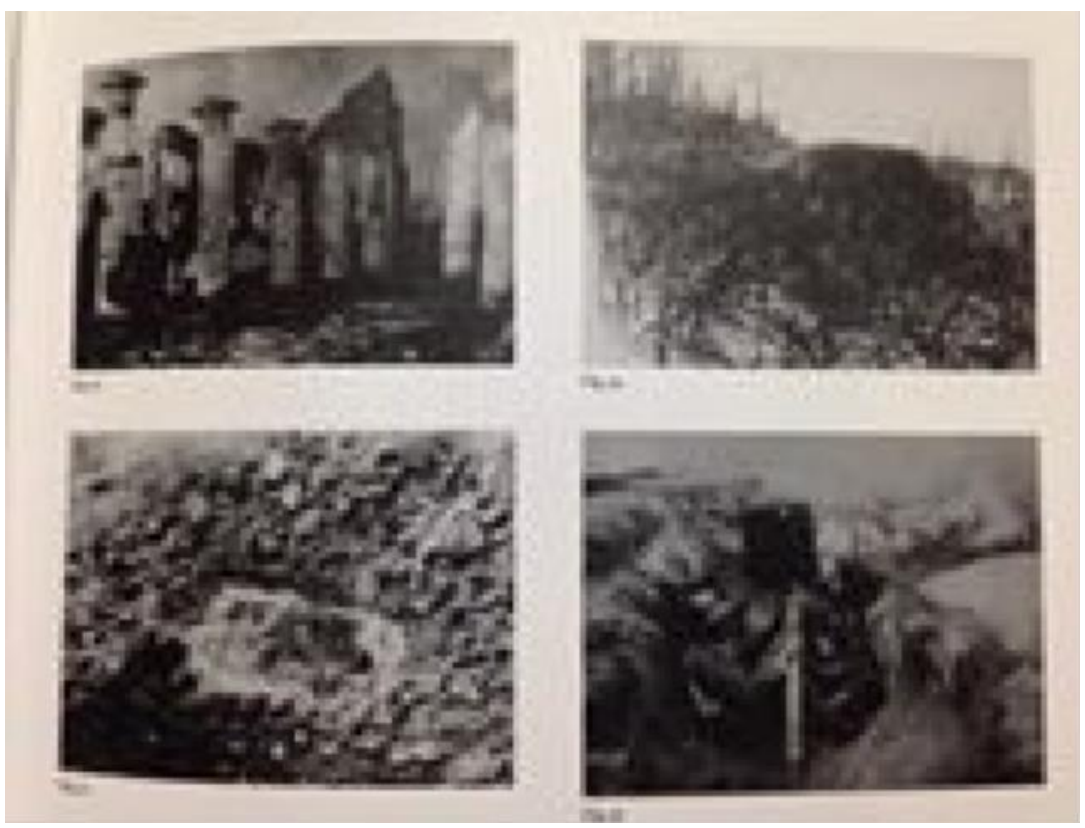

Figura 06 - Ficheiro de Guerra, 1914-1918, The Warburg Institute Archive ${ }^{7}$

Em 2002, Claudia Wedepohl, investigadora do Intituto Warburg em Londres, analisou as três caixas de fichas que restaram (das setenta e duas) numeradas 115, 117 e 118 , que se encontram nos arquivos do Instituto, revelando o imenso trabalho conduzido por Warburg e seus colaboradores na recolha inconográfica. A caixa 115 , denominada "Guerra e cultura", faz o inventário dos objetos (medalhas, postais, museus de guerra) e dos utensílios teóricos necessários à interpretação. A caixa 117 é dedicada às supertisções da guerra, e a caixa 118, intitulada "Guerra e arte" reune desde postais e imagens de

\footnotetext{
${ }^{7}$ DIDI-HUBERMAN, 2013, s/n
} 
propaganda, até aos manifestos futuristas de Marinetti, revelando não só o projeto warburguiano, mas da sua metodologia, intrinsicamente contemporânea, fazendo um uso bastante sofisticado da imagem técnica.

Através da composição estética das imagens, estes álbuns buscaram enfatizar ideia de testemunha dos eventos, passada pelas imagens individuais, e assim construir uma narratividade que servisse aos seus ideais políticos. De forma análoga, a história da arte sem palavras de Warburg, se baseia na construção de significados a partir da montagem de fotografias nos painéis do Atlas Mnemosyne. O grande arquivo por ele reunido ganharia sentido a partir do modo com o qual seria montado. Tais usos sofisticados da fotografia não eram ainda amplamente praticados fora da Alemanha. Este tempo de guerra mais distendido, compartilhado por Warburg, Friedrich e Jünger, foi o momento da consolidação de uma cultura visual baseada na imagem fotográfica.

Mas recentemente, Didi-Huberman, vai retornar à obra de Aby Warburg para através da disposição de imagens num "Atlas" oferecer uma interpretação complexa sobre as imagens do mundo, na qual venha à luz o carácter simbólico e patológico das mesmas, cuja força não cessa de operar na história. Ativo defensor de uma reformulação do discurso sobre a História a partir da importância das imagens, Huberman afirma:

(...) Olhar uma imagem é um ato contemplativo. Faz-se isso num arquivo, num museu, numa biblioteca, num ateliê de artista, num quarto. Eu tenho a impressão de ter passado minha infância em um mundo de imagens, isto é, grosso modo, em um mundo retirado da ação. Em maio de 1968 eu tinha quinze anos, todos meus amigos próximos ocupavam o liceu, protestavam nas ruas e eu olhava tristemente as coisas de minha janela, sem uma palavra, tentando ter uma ideia. Havia nessa lacuna, creio eu, medo, simplesmente. As imagens podem nos colocar na lacuna da ação, mas elas nos colocam diretamente no centro do medo. Ou, ao menos, elas sublinham, desenham, acentuam o medo. Eu the falei sobre o ateliê de meu pai: um lugar para arte, para a beleza, para a consolação e para a dimensão erótica das imagens. Mas isso foi somente a metade da experiência. A outra metade - que "quebrava" literalmente a primeira - encontrava-se na biblioteca materna: e eram todas as imagens da guerra, numa propedêutica do horror histórico, no inverso absoluto de toda beleza, no inconsolável e na dimensão enlutada das imagens. Essa tensão, parece-me, abre já na imagem a dimensão do político. $O$ que chamei de experiência de abertura, a inquietude do contato entre a imagem e o real, não é mais que, para concluir, uma ascensão à dimensão política das imagens, ao menos à sua dimensão histórica: seu papel de testemunha, isto é, de instrumento, nas grandes violências políticas. (POTTE-BONNEVILLE \& ZAOUI, 2006, s/n) 
A exposição Mémoire des Camps, organizada por Clément Cheroux em 2001 em Paris, dedica-se na análise de quatro fotografias feitas no campo de concentração de Auschwitz-Birkenau por um Sonderkommando (grupo de prisioneiros judeus que removiam os corpos dos mortos e ajudavam os nazis noutras tarefas). Desconhecidas até há pouco tempo, mostram, pela primeira vez, o processo de tortura durante o Holocausto. O que as imagens vêm mostrar é a hipótese de reconstrução do testemunho, até aqui feito pela palavra em detrimento da imagem.
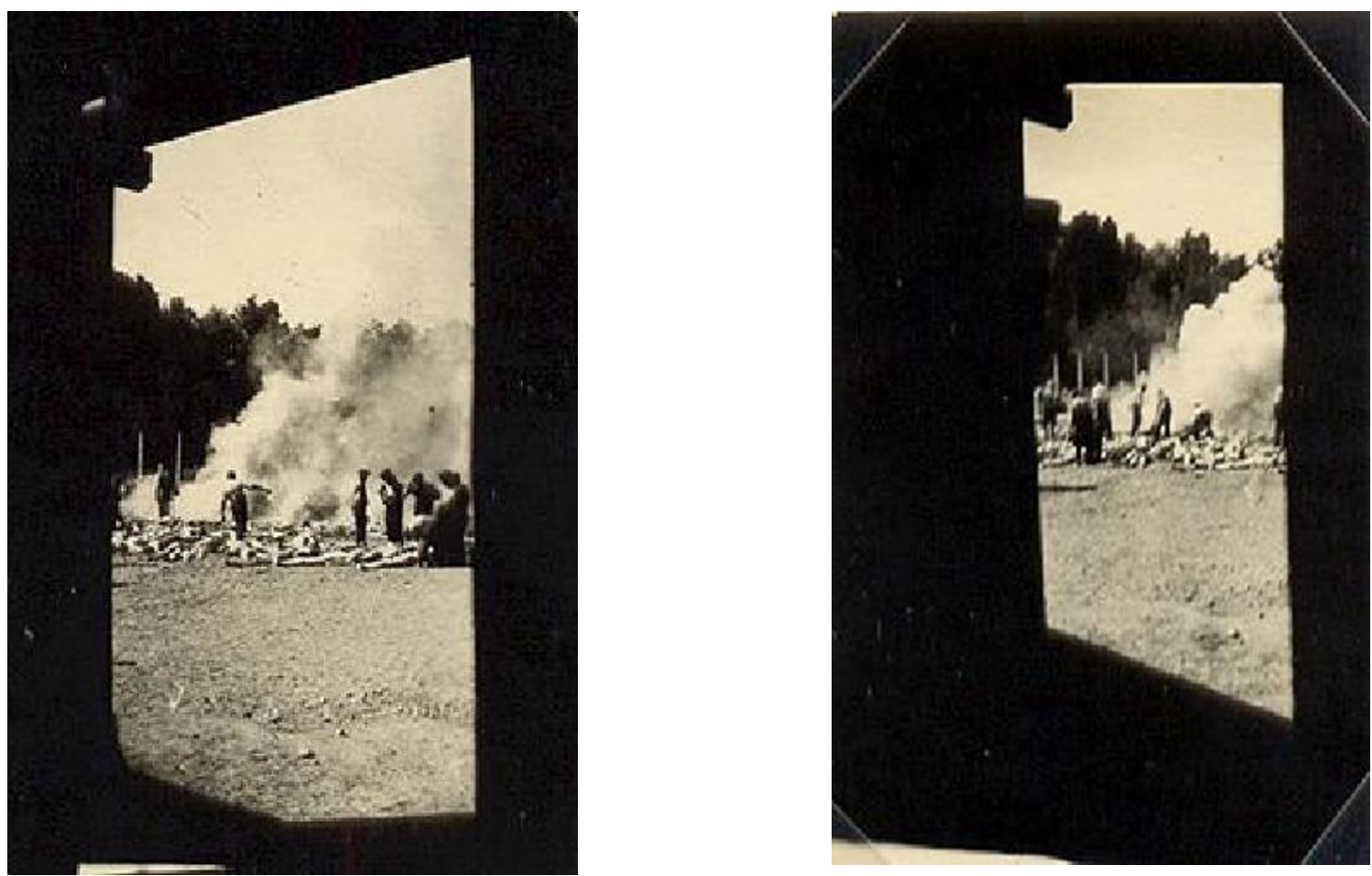

Figura 07 e 08 - Sonderkommando Photographics, 1944, Birkenau/ Auschwitz, autor desconhecido ${ }^{8}$

\footnotetext{
${ }^{8}$ DIDI-HUBERMAN, 2012, p. 26-27
} 

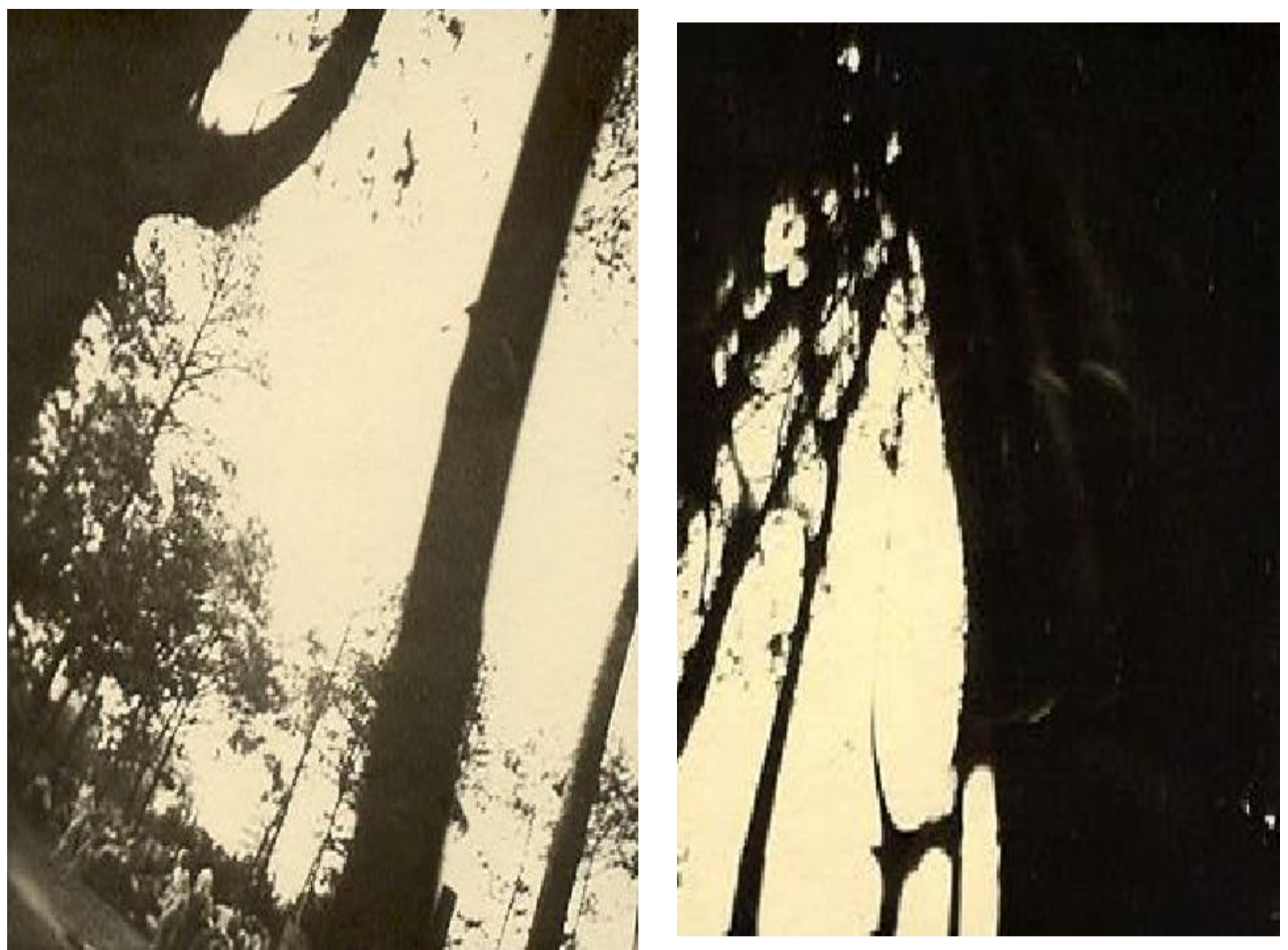

Figura 09 e 10 - Sonderkommando Photographics, 1944, Birkenau/ Auschwitz, autor desconhecido ${ }^{9}$

Estas quatro fotografias do Sonderkommando foram realizadas pelos prisioneiros de Birkenau em risco de vida e são, aos olhos de Didi-Huberman, testemunhos visuais aos quais deve-se prestar toda a atenção. São, no momento, as únicas imagens do género que se conhece. O teórico francês analisa as fotografias perguntando pelas condições em que determinadas fontes visuais podem ser utilizadas como um documento histórico, questionando o conceito de "inimaginável", defendido por Claude Lanzmann, diretor do documentário Shoah. Lanzmann insiste na idéia de que o Holocausto é inimaginável, e por isso irrepresentável. Para ele, qualquer tentativa de representação visual desse horror seria sintoma de um fetichismo revisionista. Contra esse argumento, apesar de tudo, DidiHuberman defende que as imagens podem revelar o real, pelo menos de alguma forma (DIDI-HUBERMAN, 2012). Só assim, diz Didi-Huberman, o visitante atual de Auschwitz entende que não caminha apenas em um museu, e sim "no maior cemitério do mundo". Analisar imagens antigas é como andar por uma ruína. Quase tudo está destruído, mas resta

\footnotetext{
${ }^{9}$ DIDI-HUBERMAN, 2013, p. $28-29$
} 
algo. O importante é como nosso olhar põe esse algo em movimento. Quem não sabe olhar atravessa a ruína sem entender e conluí:

(...) Não há imagens que, em si, nos deixariam mudos, impotentes. Uma imagem a respeito da qual não poderíamos dizer nada é geralmente uma imagem para a qual não lhe dedicamos o tempo - mas esse tempo é longo, ele demanda coragem, repito - de olhar atentamente. De re-inquietar-se a cada instante. (POTTE-BONNEVILLE \& ZAOUI, 2006, s/n)

\section{Considerações Finais}

O fotógrafo e o artista, por vezes, apresentam-se como mediadores dessa relação. Entre as fotografias, Sontag destaca aquelas que retratam catástrofes como uma modalidade que veicula um forte conteúdo moral. Nossos olhos não conseguem desviar-se de uma cena de aniquilação e mantêm-se fixos até o desenlace final, segundo Sontag (2003), por obrigação ou compromisso moral. Não é lícito virar o rosto e fingir que nada aconteceu. Há um engajamento inicial com a dor do outro que se desfaz pela percepção de nossa impotência diante dos fatos. Sontag evita enquadrar as reações do observador-espectador como frutos de uma sociedade do espetáculo em que tudo, inclusive a dor do outro, é reduzido ao espetáculo. A filósofa recusa essa perspectiva, atribuindo-a a um grupo diminuto da humanidade relativamente imune às ameaças das guerras: os intelectuais aos quais os fatos chegam sob a forma de espetáculo. Para todo o resto do mundo, a catástrofe pode parecer absolutamente real e possível.

Nas fotografias, Sontag (2003) vê algo além das imagens impactantes e violentas. Há por trás da câmera um fotógrafo que, de certa forma, foi exposto ao mesmo terror e estado de tensão expressos pelas imagens. Esteve prestes a ser atingido e a se transformar em mais uma vítima de guerra. Sontag reconhece a fotografia como um registro autêntico da experiência desses profissionais. Por ser uma linguagem que parece dispensar códigos específicos, a fotografia, conforme concebe Sontag (2003), tem um amplo potencial de circulação e pode ser lida por todos.

Para Sontag, a fotografia desloca a imagem de seu contexto original para evocar uma experiência de dor universal. A morte e a dor são apresentadas em uma versão universalmente humana. Essa capacidade de comunicação imediata e desembaraçada de vocabulário cria uma ilusão de experiência auto-evidente, de verdade irrefutável que se impõe ao olhar. A mediação permanece obscurecida. Na representação da dor do outro, a 
fotografia é um meio incisivo e penetrante. Tal como o provérbio ou a máxima, a fotografia, em sua forma sucinta e direta, facilita a memorização e dessa maneira é capaz de transformar imagens em emblemas de uma catástrofe. Porém a repetição e a ampla divulgação podem transformar o choque em clichê.

O século XX e este em que vivemos, podem ser denominados como os séculos das imagens, pois nunca em tão pouco tempo foram produzidas tantas imagens, sejam elas através das câmeras fotográficas de profissionais, como pela camêra de qualquer celular, potencializando a divulgação de cenas chocantes em tempo imediato. Segundo Hartman (2000), a divulgação e circulação incessantes de imagens sobre eventos traumáticos podem suscitar um "trauma secundário" no espectador. Por outro lado, a exposição exacerbada de imagens de extrema violência rotiniza o choque e pode provocar uma dessensibilização ou um surpreendente "efeito de irrealidade".

Didi-Huberman com a sua reflexão sobre as imagens, nos faz olhar e pensar a história através das imagens, através das suas sobrevivências, indo buscar esta referência em Warburg, nas Nacheleben. A imagem, não apenas a artística, é uma formação trabalhada por tempos diferentes, por anacronismos, e que não é possível compreendê-la se não a considerarmos como manifestação antropológica, fazendo apelo a uma análise que não pode ser apenas estético-formal. Retornando para as fotografias analisadas por DidiHuberman de autoria dos Sonderkommando, elas reforçam a importância das imagens como documento histórico, as imagens que podem prestar testemunho, como no caso destas quatro imagens acima citadas, que para além de serem chocantes, traça um discurso sobre a "infigurabilidade", a "irrepresentabilidade", a "inimaginabilidade" do Holocausto.

Portanto, para Didi-Huberman, as imagens não dão tudo e por vezes nos paralisam. Sontag (1986), em Ensaios sobre a fotografia escreve: "As imagens paralisam. As imagens anestesiam. Um acontecimento conhecido através da fotografia torna-se certamente muito mais real [...] Mas também se poder tornar menos real após a repetida exposição às imagens."(p. 28). Mas temos que estar atentos ao duplo regime das imagens, segundo DidiHuberman, um fluxo e refluxo da verdade que elas manifestam, conceito que Sontag define como "protótipo da revelação moderna":

É por revelarem qualquer coisa de original que as fotografias podem causar impacto. (...) O primeiro contato com o inventário fotográfico do horror 
absoluto é uma espécie de revelação, o protótipo da revelação moderna: uma epifania negativa. No meu caso, foram as fotografias de Bergen-Belsen e Dachau que descobri por acaso numa livraria de Santa Mónica em Julho de 1945. Nunca vi nada, quer em fotografias, quer na vida real, que me atingisse de um modo tão claro, profundo e instantâneo, na verdade, é possível dividir a minha vida em duas partes: antes e depois de (com doze anos) ter visto essas fotografias, embora isso se passasse váriso anos antes de ter entendido completamente o seu significado. De que me serviu tê-las visto? Eram apenas fotografias, de um acontecmento de qual mal tinha ouvido falar, de um sofrimento dificilmente imaginável e sem remédio. Quando olhei para elas algo [se] quebrou. Tinha um qualquer limite, que não era apenas o do horror; senti-me irrevogavelmente magoada, ferida, mas uma parte dos meus sentimentos começou a endurecer, algo morreu, algo ainda chora. (1986, p. 28)

Toda imagem é portadora de um pensamento, pois leva consigo algo do objeto representado, seja na fotografia ou na pintura. No entanto mais importante que este pensamento, é que toda imagem é uma memória de memórias. É necessário abrir a imagem, desdobrar a imagem, inqueitar-se diante de cada imagem" (POTTE-BONNEVILLE \& ZAOUI, 2006, s/n). A fotografia da catástrofe se constitui como um testemunho, é oposta ao "acreditar que lá estavamos" ou "tornarmos o lugar de testemunha" (DIDI-HUBERMAN, 2012, p.117). Exige um pensar cuidado da imagem, um olhar estético e ético do qual dependerá a legibilidade da imagem, no sentido que Warburg e Benjamin deram a este termo.

\section{REFERÊNCIAS}

BARTHES, Roland. A Câmara Clara. Trad. Manuela Torres. Lisboa: Edições 70, s/d.

DUBOIS, Philippe. O ato fotográfico e outros ensaios. Campinas: Papirus, 1993.

DIDI-HUBERMAN, Georges. Imagens apesar de tudo. Trad. V. Brito e J. P. Cachopo. Lisboa: KKYM, 2012

. Atlas ou a Gaia Ciência Inquieta. Tradução de Renata Correia Botelho e Rui Pires Cabral. Lisboa: KKYM + EAUM, 2013.

FREUND, Gisèle. Fotografia e Sociedade. Tradução de Pedro Miguel Frade. 2. Ed.

KOSSOY, Boris. A Fotografia como Fonte Histórica: Introdução à Pesquisa e Interpretação das Imagens do Passado. São Paulo: Museu da Indústria, Comércio e Tecnologia, 1980.

HARTMAN, G. Holocausto, testemunho, arte e trauma. IN: NETROVSKI, A; SELIGMANN-SILVA, M (orgs.). Catástrofe e representação. São Paulo: Escuta, 2000.

SÁNCHEZ DURÁ, Nicolás. Ernst Jünger. Guerra, Técnica y Fotografía. València: Universitat de València, 2002. 
SAMAIN, Etienne. As imagens não são bolas de sinuca. Como pensam as imagens. IN: SAMAIN, E. (org.). Como pensam as imagens. Campinas: Editora Unicamp, 2012.

SONTAG, Susan. Ensaios sobre Fotografia. Trad. José Afonso Furtado. Lisboa: Dom Quixote, 1986 Olhando o Sofrimento dos Outros. Trad. José de Lima. Lisboa: Gótica: 2003.

TODOROV, Tzvetan. Goya à sombra das luzes. Trad. Joana Angélica d'Avila Melo. São Paulo: Companhia das Letras, 2014

Sites CONSUltados

Entrevista realizada por Mathieu Potte-Bonneville \& Pierre Zaoui e publicada na Revista Vacarme, n³7, do outono de 2006: http://www.vacarme.org/article1210.html. Tradução: Vinícius Nicastro Honesko. Acesso em 01/2015.

https://www.academia.edu/7194083/DIANTE DA DOR DOS OUTROS. Acesso em 01/2015.

http://coral.ufsm.br/lav/noticias1 arquivos/realismo.pdf. Acesso em 01/2015. 